\title{
Decontamination efficacy of erbium:yttrium-aluminium-garnet and diode laser light on oral Candida albicans isolates of a 5-day in vitro biofilm model
}

\author{
Sabine Sennhenn-Kirchner • Peter Schwarz • \\ Henning Schliephake • Frank Konietschke • \\ Edgar Brunner • Margarete Borg-von Zepelin
}

Received: 14 November 2007 / Accepted: 19 March 2008 / Published online: 6 May 2008

(C) The Author(s) 2008

\begin{abstract}
The different forms of superficial and systemic candidiasis are often associated with biofilm formation on surfaces of host tissues or medical devices. The biofilm formation of Candida spp., in general, necessitates significantly increased amounts of antifungal agents for therapy. Often the therapeutic effect is doubtful. A 5-day biofilm model with oral Candida isolates was established according to Chandra et al. [39](J Dent Res 80:903-908, 2001) on glass and titanium surfaces and was modified by Sennhenn-
\end{abstract}

\author{
S. Sennhenn-Kirchner $\cdot$ H. Schliephake \\ Department of Oral and Maxillofacial Surgery, \\ Georg-August University of Goettingen, \\ Göttingen, Germany \\ P. Schwarz \\ Institute of Anatomy, Georg-August University of Goettingen, \\ Göttingen, Germany \\ F. Konietschke $\cdot$ E. Brunner \\ Institute of Medical Statistics, \\ Georg-August University of Goettingen, \\ Göttingen, Germany \\ M. Borg-von Zepelin \\ Reference Center for Clinical Mycoses, \\ Georg-August University of Goettingen, \\ Göttingen, Germany \\ M. Borg-von Zepelin \\ Laboratory Lademannbogen, \\ Hamburg, Germany \\ S. Sennhenn-Kirchner $(\square)$ \\ Abteilung für Mund-, Kiefer-, Gesichtschirurgie, \\ Universitätsmedizin, \\ Robert-Koch-Strasse 40, \\ 37075 Göttingen, Germany \\ e-mail: se.ki@med.uni-goettingen.de
}

Kirchner et al. [40](Z Zahnärztl Implantol 3:45-51, 2007) to investigate different aspects unanswered in the field of dentistry. In this model, the efficacy of erbium:yttriumaluminium-garnet (Er:YAG) light $(2940 \mathrm{~nm}, 100 \mathrm{~mJ}$, $10 \mathrm{~Hz}, 300 \mu \mathrm{s}$ pulsed mode applied for $80 \mathrm{~s}$ ) and diode laser light $(810 \mathrm{~nm}, 1 \mathrm{~W}$, continuous wave mode applied for $20 \mathrm{~s}$ with four repetitions after $30 \mathrm{~s}$ pauses each) was evaluated and compared to untreated controls. The photometric evaluation of the samples was completed by observations on morphological changes of yeast cells grown in the biofilm. Compared to the untreated controls Candida cells grown in mature in vitro biofilms were significantly reduced by both wavelengths investigated. Comparison between the different methods of laser treatment additionally revealed a significantly greater effect of the Er:YAG over the diode laser. Scanning electron microscopy findings proved that the diode laser light was effective in direct contact mode. In contrast, in the areas without direct contact, the fungal cells were left almost unchanged. The Er:YAG laser damaged the fungal cells to a great extent wherever it was applied.

Keywords Oral biofilm · In vitro model $\cdot$ Laser light . Surface decontamination - Candida albicans biofilm

\section{Introduction}

Manifestations of candidiasis are associated with biofilm formation occurring on surfaces of host tissues and medical devices [1,2]. Candida albicans is the most frequently isolated causative pathogen of candidiasis [3], and the network of the biofilm displays significantly increased levels of resistance to conventional antifungal agents [4]. 
The dimorphic yeast $C$. albicans can be either a commensal or an opportunistic pathogen that can cause a variety of infections, ranging from superficial mycoses to life-threatening illnesses [5].

In elderly patients, oral Candida albicans strains occur at a frequency above average, especially in patients wearing dentures $[6,7]$. These dentures are frequently combined with dental implants. A causal relationship between a persisting biofilm on the implant surface and the occurrence of peri-implant inflammation has been clinically established. The proof of colonisation of certain bacteria and yeasts was associated with peri-implant infections, in some cases even with loss of implants [8-12].

One concept for prevention and therapy of peri-implant infections is the decontamination of the surface, which leads to a reduction in the number of pathogenic microbes on the implant surface [12]. In cases of biofilm-associated infections with fungi it is important to increase the efficacy of treatment. The reason is a reduced susceptibility of $C$. albicans towards conventional treatment approaches [4].

The antimicrobial activity of laser light, which depends on its photothermic effects, has been evaluated both in vitro and in vivo [13-21], but there are few studies reporting on the effect of laser light on fungal biofilms [22-24]. Our study evaluated the efficacy of two different laser wavelengths [an erbium:yttrium-aluminium-garnet (Er:YAG) laser with a wavelength of $2940 \mathrm{~nm}$ and diode laser with $810 \mathrm{~nm}$ wavelength] on different oral strains of Candida albicans grown in a 5-day biofilm.

\section{Materials and methods}

Yeast strains and growth conditions

Two clinical oral isolates of Candida albicans were used in the study. The first $C$. albicans strain, named SK1, was a clinical oral isolate from a patient suffering from a total denture stomatitis. The second $C$. albicans strain, named SK2, was a clinical oral isolate derived from an immunocompromised patient with oral mycosis. After $12 \mathrm{~h}$ of growth in glucose broth at $37^{\circ} \mathrm{C}$, the Candida cells were harvested at the end of the logarithmic growth phase. Then, the yeast cells were washed three times with phosphate-buffered saline (PBS, pH 7.0) and standardised to $1 \times 10^{7}$ cells $/ \mathrm{ml}$.

\section{Biofilm formation}

The biofilm was established on the basis of Chandra et al. [39] and modified as follows: $100 \mu \mathrm{l}$ of the standardised $C$. albicans cell suspension was put onto the surfaces of small discs placed in a 24-well tissue culture plate (Corning No 3524, Corning Inc., New York, USA). Either round glass slides (Menzel, Braunschweig, Germany), $12 \mathrm{~mm}$ in diameter, or machined titanium devices of the same diameter (Friadent, Mannheim, Germany) were used, covered with foetal calf serum (Biochrom, Berlin, Germany) for $24 \mathrm{~h}$ before the Candida cells were allowed to adhere for $90 \mathrm{~min}$ at $37^{\circ} \mathrm{C}$ (adhesion phase). After that time, non-adherent cells were removed from the slips by being gently washed with $2 \mathrm{ml}$ PBS. The discs were then submerged in $2 \mathrm{ml}$ of brain heart infusion broth (Oxoid, Wesel, Germany) and incubated for 5 days at $37^{\circ} \mathrm{C}$. This medium was replaced every $24 \mathrm{~h}$ by the same new medium. Discs with no cells on their surfaces were treated in the same way and were used as negative controls. Control and experimental slips were incubated at $37^{\circ} \mathrm{C}$ for 5 days (biofilm growth phase).

\section{Quantitative measurement of the biofilms}

The biofilm mass was measured according to the method of Chandra et al. with a colorimetric assay that determines mitochondrial dehydrogenase activity, an indicator of the metabolic state of the fungal cells. This assay is based on the metabolic reduction of 2, 3-bis (2-methoxy-4-nitro-5sulphophenyl)-5-((phenyl amino) carbonyl)-2H-tetrazolium hydroxide (XTT) to a water-soluble brown formazan product. For the quantitative measurement, the discs with biofilms were transferred to new 24-well tissue culture plates containing $2 \mathrm{ml}$ PBS per well. To each well were added $25 \mu \mathrm{XTT}(1 \mathrm{mg} / \mathrm{ml}$ in PBS$)$ and $2 \mu$ menadione solution $\left(1 \mathrm{mM}\right.$ in acetone). Plates were incubated at $37^{\circ} \mathrm{C}$ for $5 \mathrm{~h}$. The entire contents of the well were transferred to a tube and centrifuged $(5 \mathrm{~min}, 10,000 \mathrm{~g}$ ). The amount of XTT-formazan in the supernatant was determined spectrophotometrically at $492 \mathrm{~nm}$.

Exposure of the Candida biofilms to laser irradiation

The antimicrobial efficacies of two different laser wavelengths were studied. The parameters to be applied were chosen according to clinical evaluations [19, 23].

The Elexxion duros laser (Elexxion, Radolfzell, Germany) was employed, representing both an $810 \mathrm{~nm}$ wavelength diode laser and a $2940 \mathrm{~nm}$ wavelength Er: YAG laser.

1. Diode laser light of $810 \mathrm{~nm}$ wavelength was applied in slight contact mode with a $600 \mu \mathrm{m}$ fibre in continuous wave mode $(\mathrm{cw})$ at $1 \mathrm{~W}$ for $80 \mathrm{~s}$. After each $20 \mathrm{~s}$ irradiation time a $30 \mathrm{~s}$ pause for cooling was included in the regimen [19]. The power density represented $353.7 \mathrm{~W} / \mathrm{cm}^{2}$.

2. Er:YAG laser light of $2940 \mathrm{~nm}$ wavelength was applied in pulsed mode $(100 \mathrm{~mJ}, 10 \mathrm{~Hz}, 300 \mu \mathrm{s}$ per 
pulse), also for $80 \mathrm{~s}$ irradiation time. The $800 \mu \mathrm{m}$ sapphire application tip was continuously cooled with sterile deionised water during the application of laser light and kept at a distance of $0.5 \mathrm{~mm}$ to $1 \mathrm{~mm}$ from the irradiated surface. According to the $13^{\circ}$ divergence the energy density represented $12.0 \mathrm{~J} / \mathrm{cm}^{2}$ and $15.2 \mathrm{~J} / \mathrm{cm}^{2}$.

In order to test the efficacy of the laser irradiation regimen under conditions relevant for clinical situations, we irradiated the Candida biofilms for $80 \mathrm{~s}$ at room temperature. After removal of the growth medium, the discs were taken from the well plates and irradiated at the laser wave lengths described above. The treatments were performed by an oral surgeon conversant with laser application.

The irradiation time for both kinds of slides, for the diode as well as for the Er:YAG laser, added up to $80 \mathrm{~s}$. According to the absorption spectrum of the diode laser, the glass slides were placed on a dark sterile background and were irradiated unilaterally. The titanium sleeves were irradiated from both sides. Irradiation was performed at least in duplicate at six different times.

Two glass slides and two titanium slides were left untreated and served as controls.

After treatment, irradiated and control slides were submerged in $2 \mathrm{ml}$ PBS. No extra rinsing was performed.

The remaining Candida cells were then photometrically measured using the XTT-formazan method described above. Each test was performed at least in duplicate, and all values were obtained from sixfold application.

\section{Scanning electron microscopy}

Two more samples of the in vitro Candida biofilm on glass and titanium were fixed at the end of the laser application with freshly prepared paraformaldehyde $(2 \%$ in PBS, Serva, Heidelberg, Germany), for at least $24 \mathrm{~h}$ at $8^{\circ} \mathrm{C}$. The samples were dehydrated with ethanol $(60-100 \%)$ and dried by the critical point method according to the instructions of the manufacturer (Polaron, Watford, UK). They were then sputtered with gold-palladium (Fisons Instruments, Uckfield, UK) prior to evaluation by scanning electron microscopy (SEM) (Zeiss DSM 960, Oberkochen, Germany) at $15 \mathrm{kV}$.

Each sample was qualitatively analysed to establish the number of Candida cells at the end of the laser procedure, their form, and the integrity of the fungal cells.

Statistical evaluation

Data were analysed with SAS 9.1 software (SAS Institute Inc., Cary, NC, USA). We used a heteroscedastic mixed linear model analysis (two-factor block design) using the SAS Procedure PROC MIXED with an analysis of variance-F statistic (ANOVA-F) approximation to examine the effect of the different treatments. Multiple comparisons with the control were performed, using the closure testing principle [25]. The results were regarded as significant if the $P$ value was smaller than 0.05 .

\section{Results}

Results of in vitro laser irradiation

There were no differences in the amount of cell growth between the glass and titanium surfaces colonised by the two isolates $C$. alb. SK1 and C. alb. SK2. No significant differences were observed between the different surfaces and with the two oral Candida isolates (C. alb. SK1, $P=$ 0.4815; C. alb. SK2, $P=0.3536$ ) (Fig. 1).

The efficacy of the different treatments was similar for both surfaces, but the inter-treatment differences were significant for both $C$. alb. SK1 $(P<0.0001)$ and $C$. alb. SK2 $(P=0.0001)$.

The two lasers showed significant efficacy on vital Candida biofilms after the clinically relevant application time of $80 \mathrm{~s}$ compared to the controls as well as compared to each other.

(1) C. albicans SK1: control versus treatment by diode laser $P<0.0001$; control versus treatment by Er:YAG laser $P<0.0001$ (Table 1, Fig. 2).

(2) C. albicans SK2: control versus treatment by diode laser $P<0.0001$; control versus treatment by Er:YAG laser $P<0.0001$. Statistical significance was clearly observed for both oral Candida isolates (Table 1, Table 2 and Fig. 2).

Additionally, the statistical comparison of the diode laser versus Er:YAG laser revealed significant differences. The efficacy of the Er:YAG laser light exceeded that of the diode. The significant differences were obtained with each of the oral Candida isolates tested:

(1) C. albicans SK1: diode versus Er:YAG laser $(P<$ 0.0059).

(2) C. albicans SK2: diode versus Er:YAG laser $(P<$ 0.0001) (Tables 1 and 2; Fig. 2).

Scanning electron microscopy

Scanning electron microscopy was performed to visualise the efficacy of the two different laser wavelength compared to the controls. The complexity and the multilayer of the biofilms are clearly shown (Fig. 1). The efficacy of the diode laser light, applied in direct contact mode, is visualised in Fig. $3 a$ and $b$. The cells seem to have been 
Fig. 1 SEM image of Candida albicans biofilms grown for 5 days on glass and titanium surfaces. No morphological difference between the two isolates $C$. alb. SK1 $(\mathbf{a}, \mathbf{c})$ and $C$. alb. SK2 (b, d) colonising glass (a, b) and titanium (c, d) surfaces became obvious in the SEM evaluation. Blastoconidia and pseudomycelia could be observed. All $\times 1,000$. The bars represent $10 \mu \mathrm{m}$
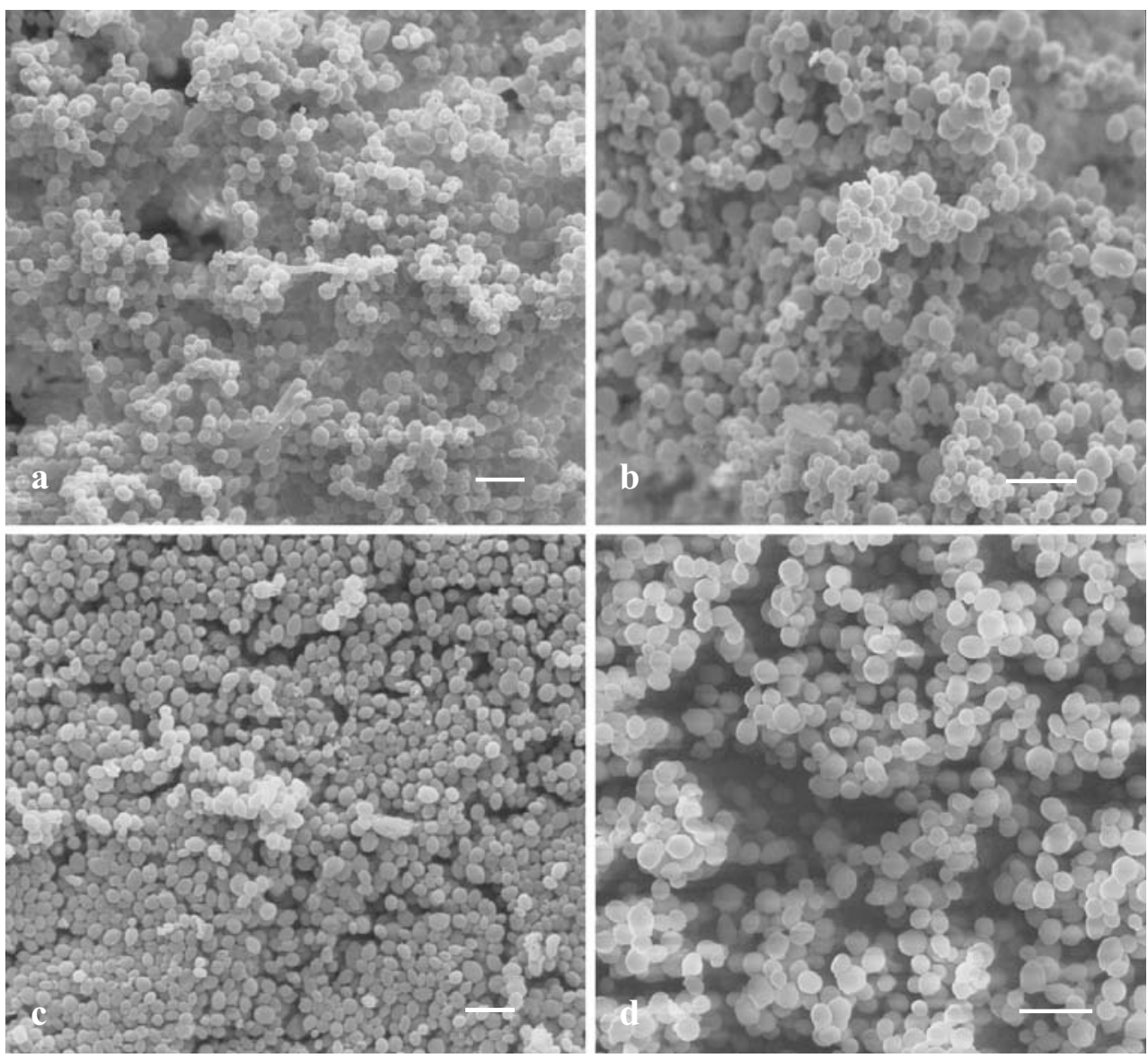

squashed and melted by direct contact with the glass fibre of the diode laser. It is obvious that the fungal cells are left almost unchanged in the other areas. In contrast to these effects, the Er:YAG laser light, in combination with water cooling, has damaged the fungal cells to a greater extent, wherever it reached the surface, and removed nearly all damaged cells from the surface of the slides (Fig. 3c and d).

\section{Discussion}

Our investigation evaluated the efficacy of diode and Er: YAG laser light on Candida albicans biofilms. The basic

Table 1 Evaluation of the laser treatment of Candida albicans SK1 on glass and titanium slides. The mean values $(492 \mathrm{~nm})$ of the photometric XTT measurement of untreated controls and treated samples after diode objectives followed SEM observations of patients with failing dental implants. Candida albicans was seen as a frequent coloniser of infected peri-implant sites, in accordance with findings of other study groups [11]. Furthermore, it has been demonstrated that the biofilm network of microorganisms leads to significantly decreased levels of susceptibility to the conventional antimicrobial and antifungal agents [4]. In vitro biofilm models have been established on various surfaces to investigate different antimicrobial strategies with good reproducibility [26, 27]. In this study a biofilm model of Candida, based on the work of Chandra et al., was used and modified for the special investigational problems (see Methods).

and Er:YAG laser irradiation are depicted in bold type. They were calculated from six repetitions. The standard error $(S E)$ and minimum $(M i n)$ and maximum (Max) values are presented as well as the statistical analysis

\begin{tabular}{|c|c|c|c|c|c|c|c|}
\hline Surface & Treatment & Mean value, $492 \mathrm{~nm}$ & SE & Min & $\operatorname{Max}$ & Statistical analysis & \\
\hline Glass & Control & 0.25 & 0.04 & 0.20 & 0.31 & \multirow{6}{*}{$\begin{array}{l}\text { Control/diode, } P<0.0001 ; \\
\text { control/Er:YAG, } P<0.0001\end{array}$} & \multirow{6}{*}{$\begin{array}{l}\text { Diode/Er:YAG } \\
P<0,0003\end{array}$} \\
\hline Glass & Diode & 0.03 & 0.03 & 0.010 & 0.06 & & \\
\hline Glass & Er:YAG & 0.01 & 0.01 & 0.00 & 0.02 & & \\
\hline Titanium & Control & 0.25 & 0.05 & 0.18 & 0.30 & & \\
\hline Titanium & Diode & 0.02 & 0.03 & 0.00 & 0.06 & & \\
\hline Titanium & Er:YAG & 0.00 & 0.00 & 0.00 & 0.001 & & \\
\hline
\end{tabular}


Fig. 2 Box plots of the efficacy of the treatment of the Candida biofilms by diode and Er:YAG irradiation on glass and titanium surfaces. The results of the evaluation on the oral isolates $C$. albicans SK1 (a and b) and $C$. albicans SK 2 (c and d) are depicted, in comparison with the control values. The trial was performed at least in duplicate with six repetitions. The absolute values (OD $492 \mathrm{~nm}$ ) are depicted on the ordinates. The reduction in the viability of Candida albicans cells following the irradiation by diode and Er:YAG laser light for $80 \mathrm{~s}$ each is shown. Compared to the controls, the reduction with both laser regimens was statistically significant $(*)$. A statistically significant difference was also demonstrated for the comparison of diode and Er:YAG laser $(* *)$. $O D$ optical density
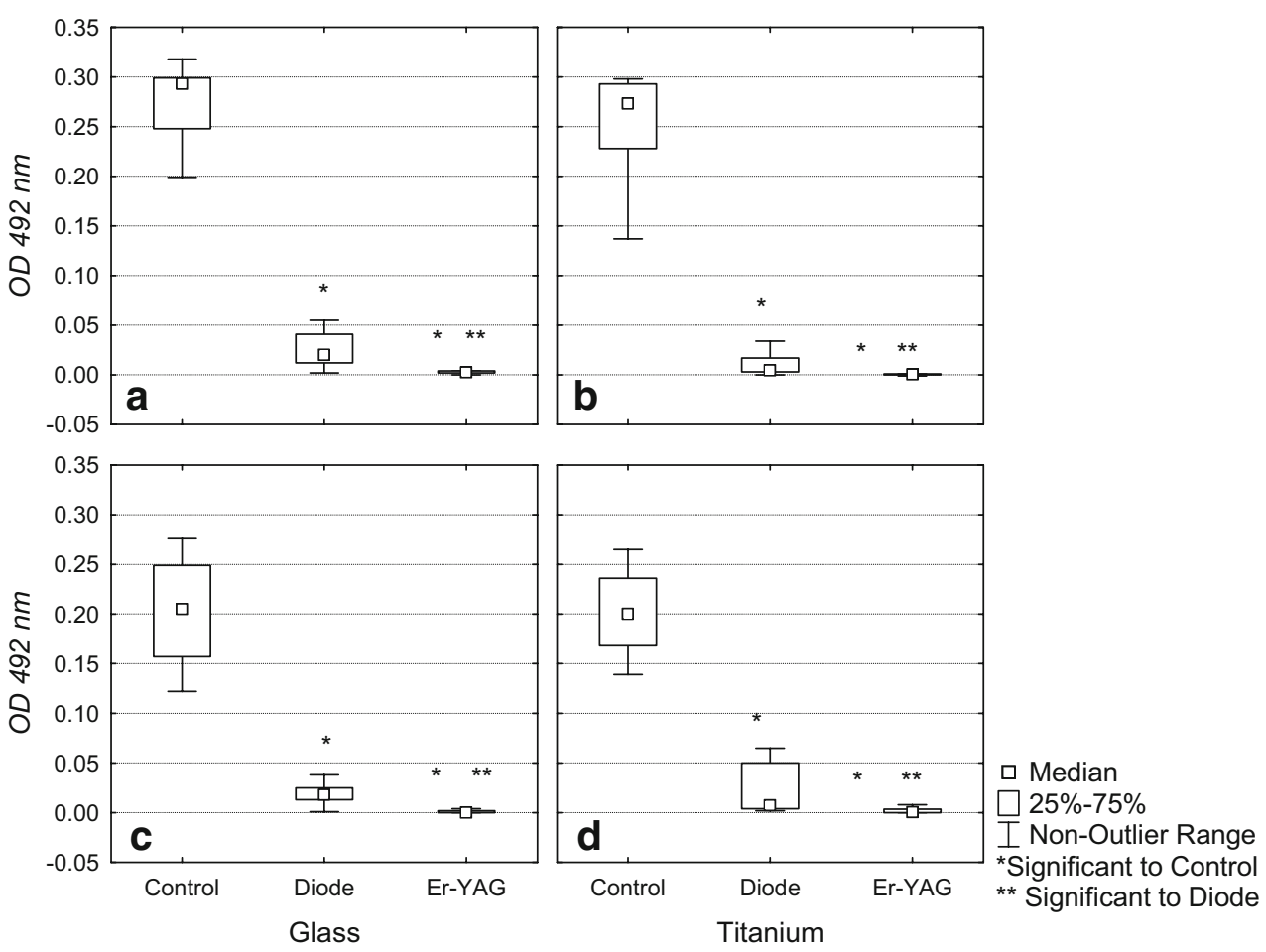

Even though the major role of periodonto-pathogens in the development of peri-implant infections has been scientifically confirmed, it has to be taken into account that the combination of bacteria and yeasts in biofilms results in an even higher pathogenic potential [28]. Particularly, elderly denture wearers show oral Candida albicans growth in frequencies above average [6,7]. C. albicans as a commensal of normal oral flora can change into an opportunistic pathogen, when the immunological situation of the host changes, by expressing several pathogenicity factors [29]. These microorganisms are able to cause a variety of severe infections in immuno-deficiency situations $[4,5]$. The peri-implant site next to rough implant surfaces reveals a decreased immune defence compared to the gingivo-periodontal situation [30,31]. Therefore, C. albicans might find an optimal environment for its conversion into an opportunistic pathogen. In combination with the decreased susceptibilities of microorganisms towards conventional methods of treatment in the situation of biofilm formation, the evaluation of the efficacy of new methods, such as laser irradiation, is of scientific interest.

The efficacy of laser light of various wavelengths to decontaminate surfaces has been demonstrated repeatedly in vitro $[14-17,32,33]$. Its clinical use in the treatment of peri-implantitis has been described [19-21], but there are only a few studies on the direct effects of laser light on oral biofilms [34-37], and the reported efficacy of the laser treatment shows great variability. Additionally, different wavelengths have been used. Rovaldi and colleges [38], for example, found a 6-log bacterial decrease by photosensitising and following $662 \mathrm{~nm}$ laser irradiation in vitro. However, the same treatment mode applied to plaque

Table 2 Evaluation of the laser treatment of Candida albicans SK2. Treatment and experimental and analytical conditions as in Table 1. SD standard deviation

\begin{tabular}{lllllll}
\hline Surface & Treatment & $\begin{array}{l}\text { Mean value, } \\
492 \mathrm{~nm}\end{array}$ & SD & Min & Max & Statistical analysis \\
\hline Glass & Control & 0.20 & 0.05 & 0.15 & 0.25 & Control/diode, $P<0.0001 ;$ \\
Glass & Diode & 0.02 & 0.01 & 0.01 & 0.03 & control/Er:YAG, $P<0.0001 \quad$ Diode/Er:YAG, \\
Glass & Er:YAG & 0.00 & 0.00 & 0.00 & 0.003 & \\
Titanium & Control & 0.23 & 0.07 & 0.16 & 0.38 & \\
Titanium & Diode & 0.02 & 0.03 & 0.00 & 0.06 & \\
Titanium & Er:YAG & 0.00 & 0.01 & 0.00 & 0.02 & \\
\hline
\end{tabular}


Fig. 3 Efficacy of the diode $(\mathbf{a}, \mathbf{b})$ and the Er:YAG (c, d) laser treatments demonstrated by SEM. a, $\mathbf{c} \times 1,000 ; \mathbf{b}, \mathbf{d} \times 3,000$. The bars represent $10 \mu \mathrm{m}$. The Candida cells seem to be squashed and melted due to the direct contact with the laser fibre (thin arrows). In other areas the fungal cells are left almost unchanged (thick arrows). In combination with the cooling water, this Er:YAG laser treatment damaged the fungal cells to a greater extent wherever it reached the surface and nearly removed the damaged cells from the surface of the slides
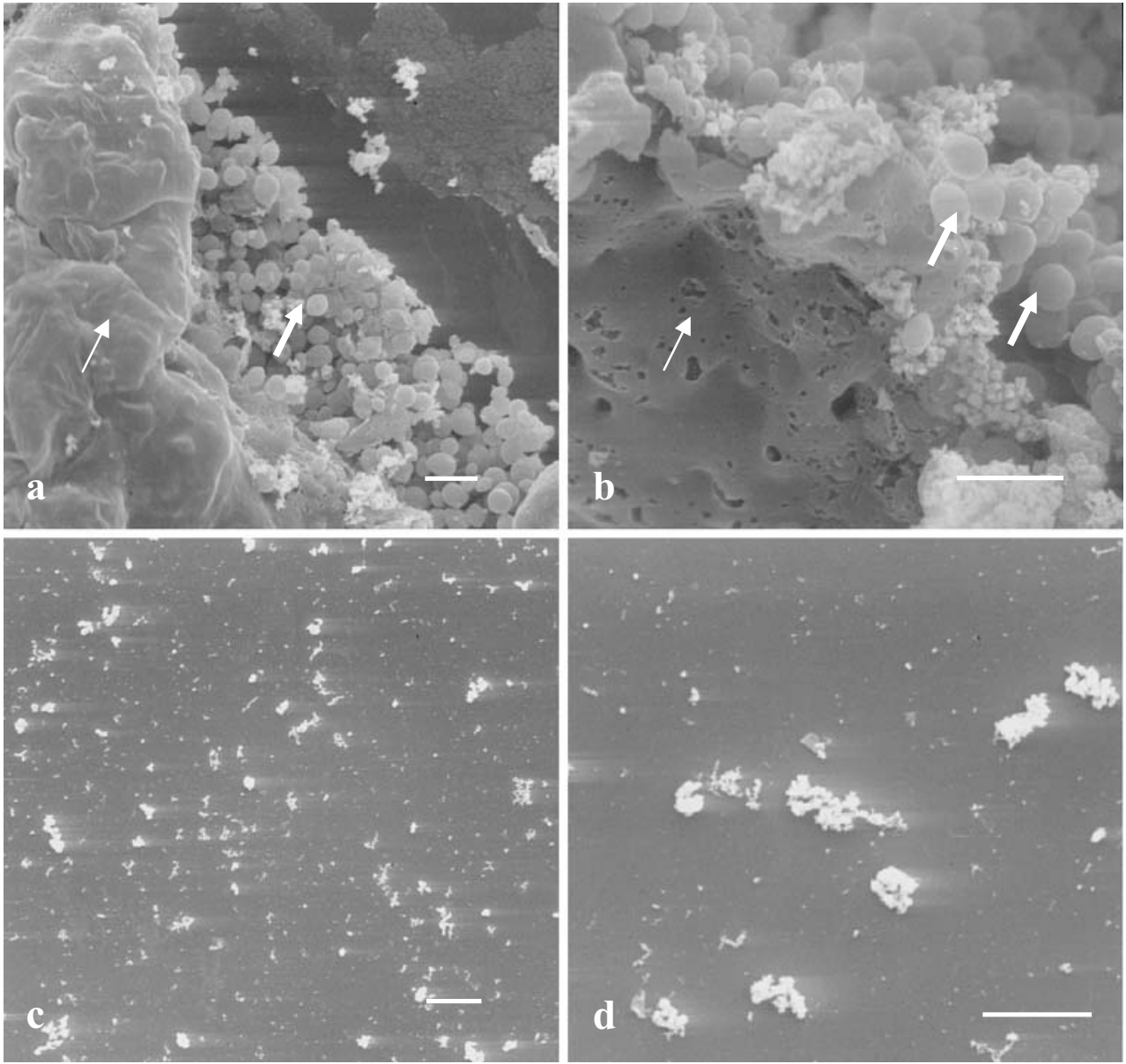

bacterial biofilm samples from periodontally affected persons by other authors only led to a $75-92 \%$ reduction, which means $a \leq 2-\log$ decrease [17]. Schwarz and colleagues found a high efficacy of Er:YAG laser irradiation on intra-orally grown early biofilms [18]. This group has shown that the efficacy of the Er:YAG wavelength increased above the effects of conventional treatment. The results of our study support the findings of Schwarz and coworkers and, furthermore, show the efficacy of the Er:YAG laser on mature Candida biofilms.

There are, likewise, only a few studies evaluating the effect of laser light on fungal biofilms [22-24]. Ward et al. determined laser light of $1,064 \mathrm{~nm}$ wavelength, applied at $10 \mathrm{~J}, 8 \mathrm{~ms}, 10 \mathrm{~Hz}$, to be effective on different bacteria and yeasts on agar plates, without changing the surface of the agar in these power settings [24]. Donnelly and co-workers used specific staining methods to increase the efficacy of laser irradiation on C. albicans biofilms on the oral mucosa to evaluate the effect of photodynamic antimicrobial therapy (PDT) on both planktonic- and biofilm-grown Candida albicans cells [22]. They found it necessary to increase photosensitiser concentration and incubation time, as well as laser light doses, over clinically capable measures to achieve high decontamination rates for Candida grown in biofilms compared to the planktonic form. The study group around De Souza [23] aimed at the effects of lowlevel diode laser radiation $(685 \mathrm{~nm})$ associated with photosensitisers on the viability of different species of Candida genus. Laser radiation in the presence of methylene blue reduced the number of colony forming units per millilitre by $88.6 \%$ for $C$. albicans. Though the PDT mode of antibacterial operation differs from that of high-power laser light, the results of our study considerably exceeded those low-level therapy results.

\section{Conclusion}

Candida albicans biofilms play a major role on mucosal surfaces and different medical devices where the immunological defence is diminished. The accumulation of the microorganisms in biofilms decreases their susceptibilities towards conventional treatment modalities. Our study was able to show the efficacy of diode light, and particularly Er: YAG laser light, on Candida albicans biofilms grown on glass and titanium surfaces after a clinically tenable 
application time. Especially, the treatment outcome on titanium surfaces makes the results valuable for laser application in the treatment of peri-implant infections. When diode laser light is applied on dental implants, adequate cooling-off times will be essential, to avoid overheating of the adjacent bone.

Acknowledgements The authors would like to express their appreciation to Cyrilla Maelicke (Department of Cell Biology, University of Goettingen), for critical review of the manuscript and linguistic assistance, and Magdalene Kolder and Sigrid Ahlborn for technical support. The study was supported by Elexxion, Radolfzell, Germany (laser equipment) and by Friadent, Mannheim, Germany, who provided the titanium discs.

Open Access This article is distributed under the terms of the Creative Commons Attribution Noncommercial License which permits any noncommercial use, distribution, and reproduction in any medium, provided the original author(s) and source are credited.

\section{References}

1. Kojic EM, Darouiche RO (2004) Candida infections of medical devices. Clin Microbiol Rev 17:255-267

2. Ramage G, Tomsett K, Wickes BL, López-Ribot JL, Redding SW (2004) Denture stomatitis: a role for Candida biofilms. Oral Surg Oral Med Oral Pathol Oral Radiol Endod 98:53-59

3. Jarvis WR (1995) Epidemiology of nosocomial fungal infections, with emphasis on Candida species. Clin Infect Dis 20:1526-1530

4. Ramage G, Saville SP, Thomas DP, López-Ribot JL (2005) Candida biofilms: an update. Eukaryot Cell 4:633-638

5. Sandven P (2000) Epidemiology of candidemia. Rev Iberoam Micol 17:73-81

6. Budtz-Jorgensen A, Stenderup A, Grabowski M (1975) An epidemiological study of yeasts in elderly denture wearers. Community Dent Oral Epidemiol 3:115-119

7. Berdicevsky I, Ben-Aryeh H, Szargel R, Gutman D (1980) Oral candida of asymptomatic denture wearers. Int J Oral Surg 9:113-115

8. Quirynen M, Vogels R, Peeters W, van Steenberghe D, Naert I, Haffajee A (2006) Dynamics of initial subgingival colonization of 'pristine' peri-implant pockets. Clin Oral Implants Res 17:25-37

9. Heydenrijk K, Meijer HJ, van der Reijden WA, Raghoebar GM, Vissink A, Stegenga B (2002) Microbiota around root-form endosseous implants: a review of the literature. Int $\mathrm{J}$ Oral Maxillofac Implants 17:829-838

10. Hultin M (2002) Microbiological findings and host response in patients with peri-implantitis. Clin Oral Implants Res 13:349-358

11. Leonhardt A, Bergstrom C, Lekholm U (2003) Microbiologic diagnostics at titanium implants. Clin Implant Dent Relat Res 5:226-232

12. Mombelli A, Lang NP (1992) Antimicrobial treatment of periimplant infections. Clin Oral Implants Res 3:162-168

13. Deppe H, Horch HH, Henke K, Donath K (2001) Peri-implant care of ailing implants with the carbon-dioxide laser. Int $\mathrm{J}$ Oral Maxillofac Implants 16:659-667

14. Kreisler M, Kohnen W, Marinello C, Schoof J, Langenau E, Jansen B, d'Hoedt B (2003) Antimicrobial efficacy of semiconductor laser irradiation on implant surfaces. Int J Oral Maxillofac Implants 18:706-711

15. Sennhenn-Kirchner S, Aufenanger J, Jacobs HG (2002) Decontamination efficacy of diode laser light on rough implant surfaces
- microbiological evaluation of an in-vitro study (in German). Z Zahnärztl Implantol 18:23-28

16. Schwarz F, Sculean A, Romanos G, Herten M, Horn N, Scherbaum W, Becker J (2005) Influence of different treatment approaches on the removal of early plaque biofilms and the viability of SAOS2 osteoblasts grown on titanium implants. Clin Oral Investig 9:111-117

17. Soukos NS, Mulholland SE, Socransky SS, Doukos AG (2003) Photodestruction of human dental plaque bacteria: enhancement of the photodynamic effect by photomechanical waves in an oral biofilm model. Lasers Surg Med 33:161-168

18. Romanos GE, Henze M, Banihashemi S, Parsanejad HR, Winckler J, Nentwig GH (2004) Removal of epithelium in periodontal pockets following diode $(980 \mathrm{~nm})$ laser application in the animal model: an in-vitro study. Photomed Laser Surg 22:177-183

19. Bach G, Neckel C, Mall C, Krekeler G (2000) Conventional versus laser-assisted therapy of periimplantitis: a five-year comparative study. Implant Dent 9:247-251

20. Haas R, Baron M, Doertbudak O, Watzek G (2000) Lethal photosensitization, autogenous bone, and e-PTFE membrane for the treatment of peri-implantits: preliminary results. Int $\mathrm{J}$ Oral Maxillofac Implants 15:374-382

21. Schwarz F, Bieling K, Bonsmann M, Latz T, Becker J (2006) Nonsurgical treatment of moderate and advanced periimplantitis lesions: a controlled clinical study. Clin Oral Investig 10: 279-288

22. Donnelly RF, McCarron PA, Tunney MM, David Woolfson A (2007) Potential of photodynamic therapy in treatment of fungal infections of the mouth. Design and characterisation of a mucoadhesive patch containing toluidine blue O. J Photochem Photobiol B 86:59-69

23. de Souza SC, Junqueira JC, Balducci I, Koga-Ito CY, Munin E, Jorge AO (2006) Photosensitization of different Candida species by low power laser light. J Photochem Photobiol B 83:34-38

24. Ward GD, Watson IA, Stewart-Tull DE, Wardlaw AC, Chatwin CR (1996) Inactivation of bacteria and yeasts on agar surfaces with high power Nd:YAG laser light. Lett Appl Microbiol 23:136-140

25. Marcus R, Peritz E, Gabriel KR (1976) On closed testing procedures with special reference to ordered analysis of variance. Biometrika 63:655-660

26. Suci PA, Tyler BJ (2003) A method for discrimination of subpopulations of Candida albicans biofilm cells that exhibit relative levels of phenotypic resistance to chlorhexidine. J Microbiol Methods 53:313-325

27. Thein ZM, Samaranayake YH, Samaranayake LP (2007) Characteristics of dual species Candida biofilms on denture acrylic surfaces. Arch Oral Biol 52:1200-1208

28. Hogan DA, Kolter R (2002) Pseudomonas-Candida interactions: an ecological role for virulence factors. Science 296:2229-2232

29. Monod M, Borg- von Zepelin M (2002) Secreted proteinases and other virulence mechanisms of Candida albicans. Chem Immunol $81: 114-128$

30. Lindhe J, Berglundh T, Ericsson I, Liljenberg B, Marinello C (1992) Experimental breakdown of peri-implant and periodontal tissues. A study in the beagle dog. Clin Oral Implants Res 3:9-16

31. Liljenberg B, Gualini F, Berglundh T, Lindhe J (1997) Composition of plaque associated lesions in the gingival and the periimplant mucosa in partially edentulous subjects. J Clin Periodontol 24:119-123

32. Kreisler M, Götz H, Duschner H (2002) Effect of Nd:Yag, Ho: Yag, Er:Yag, Co2 and GaAlAs laser irradiation on surface properties of endosseous dental implants. Int J Oral Maxillofac Implants 17:202-211

33. Matsuyama T, Aoki A, Oda S, Yoneyama T, Ishikawa I (2003) Effects of the Er- Yag laser irradiation on titanium implant 
materials and contaminated implant abutment surfaces. J Clin Laser Med Surg 21:7-17

34. Haas R, Doertbudak O, Mensdorff-Pouilly N, Mailath G (1997) Elimination of bacteria on different implant surfaces through photosensitization and soft laser. An in vitro study. Clin Oral Implants Res 8:249-254

35. Roos-Jansacker A-M, Renvert S, Egelberg J (2003) Treatment of peri-implant infections: a literature review. J Clin Periodontol 30:467-485

36. Esposito M, Worthington H, Coulthard P (2004) Interventions for replacing missing teeth: treatment of periimplantitis. Cochrane Database Syst Rev 4:CD004970D

37. Sennhenn-Kirchner S, Klaue S, Wolff N, Mergeryan H, Borg von Zepelin M, Jacobs HG (2007) Decontamination of rough titanium surfaces with diode lasers: microbiological findings on in vivo grown biofilms. Clin Oral Implants Res 18:126-132

38. Rovaldi CR, Pievsky A, Sole NA, Friden PM, Rothstein DM, Spacciapoli P (2000) Photoactive porphyrin derivative with broadspectrum activity against oral pathogens In-vitro. Antimicrob Agents Chemother 44:3364-3367

39. Chandra J, Mukherjee PK, Leidich SD, Faddoul FF, Hoyer LL, Douglas LJ, Ghannoum MA (2001) Antifungal resistance of candidal biofilms formed on denture acrylic in-vitro. J Dent Res 80:903-908

40. Sennhenn-Kirchner S, Cevik G, Ahlborn S, Jacobs HG, Schwarz P, Borg-von Zepelin M (2007) Decontamination efficacy of antiseptical agents on various Candida albicans isolates of a five day in-vitro biofilm model. ZZI 3:45-51 